Research, part of a Special Feature on Effects of Roads and Traffic on Wildlife Populations and Landscape Function

\title{
Large Gaps in Canopy Reduce Road Crossing by a Gliding Mammal
}

\author{
$\underline{\text { Rodney van der Ree }}^{1}$, Silvana Cesarini ${ }^{2}, \underline{\text { Paul Sunnucks }}^{2}, \underline{\text { Joslin L. Moore }}^{1}$, and Andrea Taylor $^{2}$
}

\begin{abstract}
Roads and traffic reduce landscape connectivity and increase rates of mortality for many species of wildlife. Species that glide from tree to tree may be strongly affected by roads and traffic if the size of the gap between trees exceeds their gliding capability. Not only are wide roads likely to reduce crossing rates, but mortality may also be increased if gliders that do cross have poor landing opportunities. The road-crossing behavior of 47 squirrel gliders (Petaurus norfolcensis) was investigated in southeast Australia using radio-tracking. The proportion of gliders crossing one or both roadways of a freeway where trees were present or absent from the center median was compared to that at single-lane country roads (control). The proportion of gliders crossing the road at control sites $(77 \%)$ was similar to the proportion that crossed one or both roadways at the freeway with trees in the median $(67 \%)$, whereas only a single male $(6 \%)$ crossed the freeway where trees were absent from the median. The frequency of crossing for each individual was also similar at control sites and freeway sites with trees in the median. The almost complete lack of crossing at sites where trees were absent from the median was attributed to the wider gap in canopy (50 - 64 m vs. 5-13 m at sites with trees in the median). This suggests that traffic volume, up to 5,000 vehicles per day on each roadway, and the other characteristics of the freeway we studied are not in themselves complete deterrents to road crossing by squirrel gliders. This study demonstrates that retaining and facilitating the growth of tall trees in the center median of two-way roads may mitigate the barrier effect of roads on gliders, thus contributing positively to mobility and potentially to connectivity. This information will be essential for the assessment of road impacts on gliding species using population viability models.
\end{abstract}

Key Words: barrier; canopy gap; freeway; gliders; mitigation; road crossing; radio-tracking; vegetated median

\section{INTRODUCTION}

Road ecology has recently emerged as a bona fide subdiscipline within ecology and there has been increasing interest in the integration of findings of scientific research into decision making in transportation planning (Roedenbeck et al. 2007). Numerous studies have documented the adverse impacts of roads on wildlife (see reviews by Coffin 2007, Fahrig and Rytwinski 2009, Benítez-López et al. 2010), which include habitat loss, mortality due to collision with vehicles, resource inaccessibility, and population subdivision (Jaeger et al. 2005). A well-connected landscape can overcome the negative effects of habitat fragmentation on population persistence by allowing dispersal and recolonization of vacant territories, thus maintaining viable metapopulations and genetic variability (Hels and Nachman 2002, Jaeger and Fahrig 2004, Marsh et al. 2008). It is essential to quantify the barrier effect of roads on species occurring in fragmented habitat to determine any impact on population viability. Information on crossing behavior can be used to provide recommendations for optimal road planning and potential mitigation structures, and information for population viability models (Kramer-Schadt et al. 2004, Jaeger et al. 2005)

The relative importance of each of these effects, however, is often species- and habitat-specific (Litvaitis and Tash 2008). For example, chipmunks

\footnotetext{
${ }^{1}$ Australian Research Centre for Urban Ecology, Royal Botanic Gardens Melbourne, ${ }^{2}$ Australian Centre for Biodiversity, School of Biological Sciences, Monash University
} 
(Tamias striatus) and white-footed mice (Peromyscus leucopus) appear to avoid roads regardless of traffic volume (Ford and Fahrig 2008, McGregor et al. 2008), while the permeability of roads for many carnivores and ungulates is related to traffic volume (Alexander et al. 2005). Most studies on the effects of roads and other linear infrastructure have focused on terrestrial fauna that move along the ground, especially large (Kramer-Schadt et al. 2004, Epps et al. 2005, Riley et al. 2006) and small mammals (Rondinini and Doncaster 2002, Brock and Kelt 2004, Ford and Fahrig 2008), reptiles (Shine et al. 2004, Steen et al. 2006, Tanner and Perry 2007), and amphibians (Hels and Nachman 2002, Eigenbrod et al. 2008, Lengagne 2008; Marsh et al. 2008).

Gliding mammals have evolved an efficient and highly specialized way of locomotion, where a gliding membrane, the patagium, is converted into an airfoil when extended between the fore and hind limbs (Jackson 1999). Therefore, their response to potential barriers is likely to differ substantially from that of animals of comparable size that travel on the ground, and cannot be extrapolated from other species. Roads and traffic may have little effect on the movement patterns and dispersal of gliders if the size of the gap in tree cover is within their glide distance capability, and if traffic disturbance does not excessively alter their gliding behavior or rate of survival. Conversely, the movement of gliders may be severely restricted if they 1) are deterred by the long glide required to traverse the clearing, 2) avoid the road in response to traffic disturbance, and/or 3) attempt to cross the road but have increased rates of mortality as a consequence. The type of vegetation present along roads is likely to have a strong effect on the crossing ability of gliders, because of the role of trees in the gliding technique.

The squirrel glider (Petaurus norfolcensis) is a small $(\sim 250 \mathrm{~g})$, nocturnal, arboreal marsupial native to eastern Australia (van der Ree and Suckling 2008). Its preferred habitat of dry eucalypt woodland has been extensively cleared in southern Australia for agricultural and urban development and the species is now threatened with extinction in that region (Claridge and van der Ree 2004, van der Ree et al. 2004). Maximum glide lengths are approximately $70 \mathrm{~m}$ (van der Ree et al. 2003), with typical glides closer to $20 \mathrm{~m}$ (Goldingay and Taylor 2009) or $30-35 \mathrm{~m}$ in length (van der Ree and Bennett 2003, van der Ree et al. 2003). Glide length appears to be similar for males and females (Goldingay and Taylor 2009) and is related to tree height and the distance between trees, although all studies of gliding ability have been conducted in continuous forest, in semicleared farmland, or in laboratory settings. There have been no studies that systematically quantify the effect of gap size on the rate of gap crossing, which is critical to the design of roads that permit the movement of this wildlife species and ones with similar movement abilities.

The aim of this study was to examine the roadcrossing behavior of squirrel gliders resident in woodland adjacent to a major road. The traffic volume (freeway vs. secondary road), presence or absence of tall trees in the center median, and the sex of the glider were investigated as potential factors influencing crossing rates.

\section{METHODS}

\section{Study area}

The study was conducted in northeastern Victoria, Australia where approximately $5 \%$ of the original tree cover remains. Dominated primarily by agricultural land uses, the remaining woodland and forest mostly occurs as linear strips along roads and creeks and in small patches (van der Ree and Bennett 2001). The overstorey of the woodland is dominated by grey box (Eucalyptus microcarpa), river red gum (E.camaldulensis), Blakely's red gum (E. blakelyi), and yellow gum (E. leucoxylon), with acacia species (primarily golden wattle Acacia pycnantha) in the midstorey and grasses in the understorey. The overstorey trees are typically $25-30 \mathrm{~m}$ in height.

Sites were selected along the Hume Freeway, approximately $150 \mathrm{~km} \mathrm{NE}$ of Melbourne (Fig. 1). The Hume Freeway is the major highway connecting Melbourne and Sydney, and was progressively widened to dual-roadway, i.e., two lanes for each direction of traffic separated by a centre median, in the 1970s and 1980s. The average traffic volume is 10,000 vehicles per day, a quarter of which occurs between 10:00 p.m. and 5:00 a.m. (Vicroads, the Department of Transportation for the State of Victoria, Australia, unpublished data), when squirrel gliders are active. All sites were located at intersections between the Hume Freeway and secondary sealed or unsealed roads running perpendicular to the freeway (Fig. 1). Woodland vegetation occurred on the verge (defined as the area 
between the edge of the road, including any emergency stopping lane, and the road reservation) of the secondary roads from their intersection with the Hume Freeway for at least $1 \mathrm{~km}$, thus providing corridors of woodland vegetation within cleared agricultural land (Fig. 2). Intersections were selected as the focus for study because squirrel glider activity is higher at intersections than straight sections of linear habitat (van der Ree and Bennett 2003) and hence road crossing is more likely. Six sites were selected along the Hume Freeway, three of which had eucalypt trees at least $20 \mathrm{~m}$ tall in the center median (Fig. 3a) and three where the median was treeless (Fig. 3b), but may have included shrubs up to $2-3 \mathrm{~m}$ tall, denoted Trees and No-Trees, respectively. A glider was trapped in the median of the Hume Freeway $1.8 \mathrm{~km} \mathrm{SW}$ of No-Trees 3 as part of a different project. Because the maximum range length of gliders in similar linear habitats was 2580 m (van der Ree and Bennett 2003), we could not assume this individual was independent of the nearby No-Trees 3 site. Therefore, this site is referred to as No-Trees 3a (Fig. 1) and its results were pooled with No-Trees 3 for analysis. The mean width of the dual-roadway, measured from the edge of the bitumen, was $57 \mathrm{~m}$ (range: $44-76 \mathrm{~m}$ ) and the mean width of the center median was $31 \mathrm{~m}(21-$ $48 \mathrm{~m}$ ). The size of the gap in canopy connectivity at sites with trees in the median ranged from 5-13 $\mathrm{m}$ and 50-64 $\mathrm{m}$ at sites without trees in the median. Sites were at least $6 \mathrm{~km}$ apart $(\max .25 \mathrm{~km})$ and alternated between Trees and No-Trees to avoid confounding biases, e.g. vegetation type or wind patterns, thus ensuring glide length was the only substantial variable influencing the ability of gliders to cross the freeway.

To ensure that the rate of crossing by squirrel gliders at the freeway was due to the road and high traffic volumes, and not an artifact of habitat geometry, we also selected intersections between two secondary roads to act as control or reference sites (Fig. 3c). These were located $6.5 \mathrm{~km}$ (Control-1) and $9.7 \mathrm{~km}$ (Control-2) from the Hume Freeway (Fig. 1) and had a canopy gap $<9 \mathrm{~m}$. The traffic volume was $<$ 50 and $50-150$ vehicles per day (vpd) on the two roads at Control- 1 , and $<50 \mathrm{vpd}$ on both roads at Control-2.

\section{Trapping and radio-tracking}

Squirrel gliders were trapped within linear strips of woodland at the intersection between the freeway and secondary roads perpendicular to the freeway. Traps along the secondary roads extended up to 250 $\mathrm{m}$ from the freeway edge, and included the centre median, if trees were present, as well as up to 100 $\mathrm{m}$ of freeway verge. Gliders were captured using wire mesh cage traps $(17 \times 20 \times 50 \mathrm{~cm})$ nailed to tree trunks at a height of $1.5-4 \mathrm{~m}$. Traps were baited with a mixture of rolled oats, honey, and peanut butter, and honey diluted with water was sprayed on the tree trunk to a height of $5-7 \mathrm{~m}$. Trapping effort varied over time and among sites, as the objective was to capture sufficient animals for radio-tracking. Each site was trapped for an average of nine nights (range $4-15$ ), giving a total of 1532 trap nights between December 2005 and May 2006. Additional trapping was conducted to replace collars that fell off during the study, and to remove them at the end of the study.

Traps were checked each morning at dawn, and all captured animals were sexed, weighed, tattooed with a distinctive code, and their reproductive condition assessed. Animals were classed as $<1$, $1-2$ and $>2$-years old, based on upper incisor wear, body weight, and fur condition (van der Ree et al. 2006). Radio transmitters (single-stage tuned-loop, $150 \mathrm{MHz}$; Sirtrack, New Zealand) mounted on neck collars that weighed $5 \mathrm{~g}$ overall, $<5 \%$ of body weight, were fitted to up to six adults $(3 \mathrm{M}, 3 \mathrm{~F})$ per site, distributed on both sides of the freeway. If this target was not met after five nights of trapping, collars were fitted to adults of either sex, up to the maximum of six individuals per site. Juvenile squirrel gliders $(<1$ year old) were not collared because of the risk of strangulation if they dispersed while carrying collars of a fixed size and outgrew them. Furthermore, genetic methods will be used in a subsequent study to estimate the rate of successful dispersal by juveniles (rationale and approaches in Simmons et al. 2010).

Radio-tracking was undertaken between December 2005 and November 2006 using a Regal 2000 receiver and a Yagi 3-element antenna (Titley Electronics, Australia). Two types of radio-tracking fixes, directional or homing, were collected. Directional fixes were obtained by determining the direction of the animal from the road, or if it was in the center median at freeway sites, using a pair of 3 -element Yagi antennae mounted on a vehicle. The 
Fig. 1. Location of six sites along the Hume Freeway: circles $=$ sites with trees in the median (Trees), triangles $=$ sites without trees in the median (No-Trees), and two control sites (stars), in northeastern Victoria, Australia (State of Victoria shown in square in top left corner). The insert shows diagrams of the road intersection layout at Trees, No-Trees, and control sites, where diagonal lines indicate cleared agricultural land.

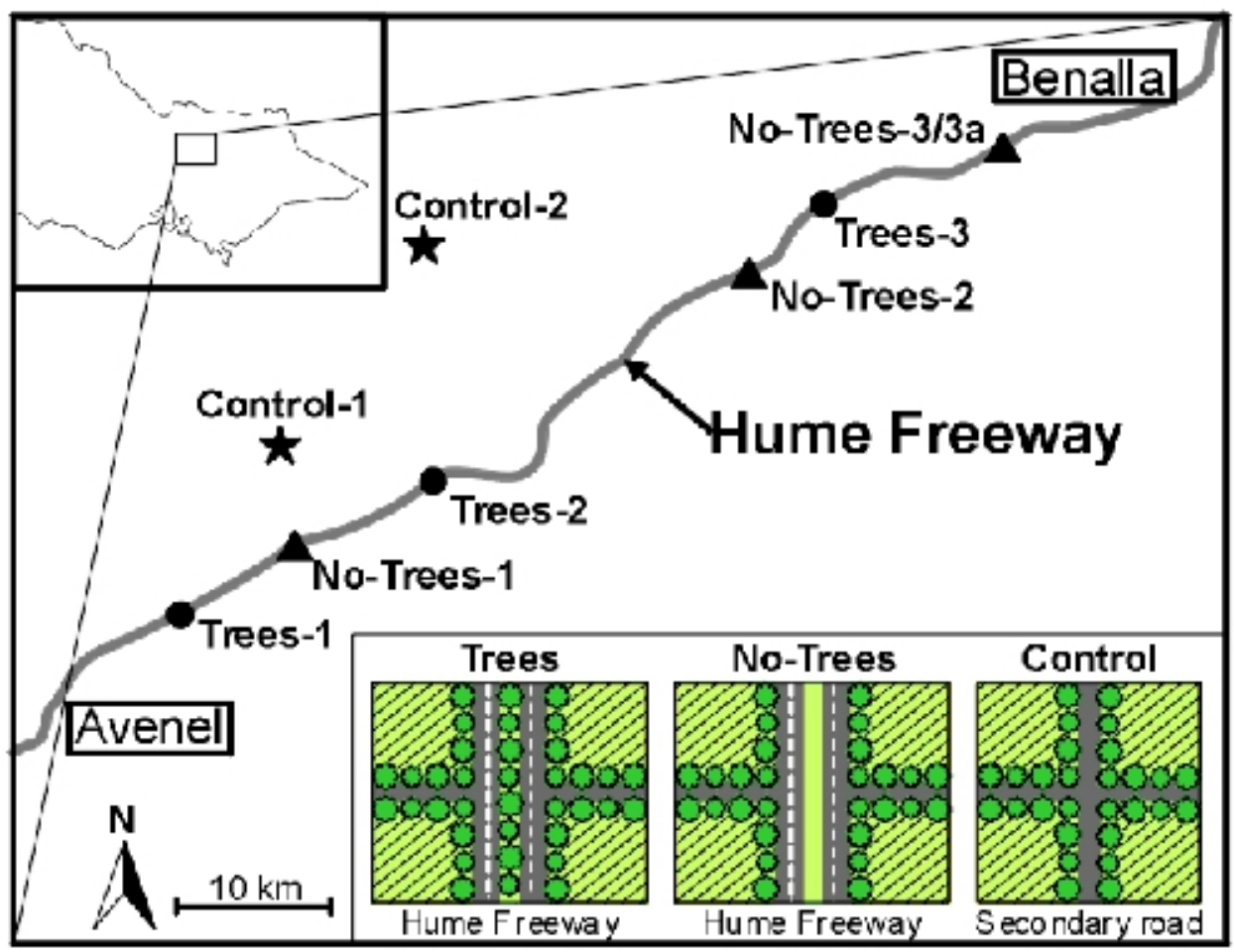

antennae were selected alternately to assess the signal strength to the left and right of the vehicle, thus determining the direction of the glider. The direction of the signal was confirmed by turning the vehicle $180^{\circ}$ from its initial position and repeating the procedure. If the direction was equivocal, tracking was performed on foot until the direction of the animal from the freeway was confirmed. Homing fixes were obtained by tracking the animal on foot and recording its exact location $( \pm 10 \mathrm{~m})$ with a GPS. Both types of fixes were collected during the day and the night, with one diurnal fix collected to identify the location or direction of den trees. All consecutive fixes were $>2$ hours apart to ensure independence, since squirrel gliders can move more than $300 \mathrm{~m}$ in $15 \mathrm{~min}$ (Holland et al. 2007), and are therefore capable of traversing the length of their home range within $2 \mathrm{~h}$. Up to three nocturnal fixes were recorded per night.
We used only those fixes that indicated movement, i.e., we inferred that the collar had malfunctioned or been removed when consecutive fixes repeatedly occurred in the same location and no further movement was detected. When a signal was not detected, radio-tracking was conducted from a vehicle using an omni-directional whip antenna over a $5 \mathrm{~km}$ radius around its usual area.

\section{Rate of crossing}

The effect of the road on the rate of crossing was quantified for those individuals who could access the road without traversing the territory of an adjacent social group. The extent of spatial overlap of home ranges between adjacent social groups of squirrel gliders is low, $\sim 14 \%$ (van der Ree and Bennett 2003), and thus the rate of crossing by individuals is likely to be affected by the presence 
Fig. 2. Aerial photograph of a section of the study area along to the Hume Freeway, northeastern Victoria, Australia. The photograph shows how remnant vegetation occurs mainly along roads (linear dark lines) and waterways. (Source: GoogleTM, 2009).

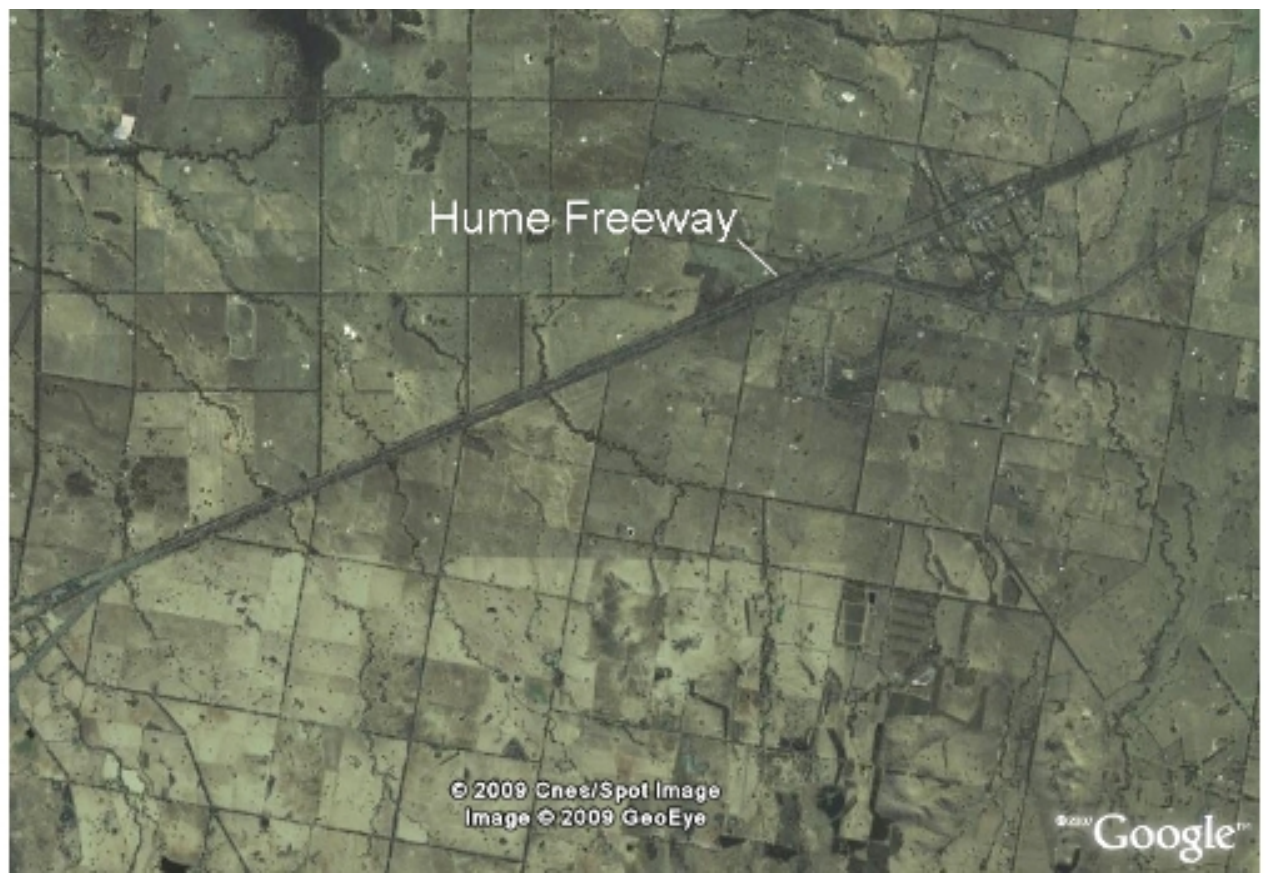

of an adjacent social group if their territories need to be crossed to reach the road. Therefore, only gliders with a homing fix or trap capture $<250 \mathrm{~m}$ from the road edge were included for analysis, because the shortest mean range length of gliders in similar linear habitats was $322 \mathrm{~m}( \pm 77$ s.e.; van der Ree and Bennett 2003). To avoid underestimating crossing behavior, only gliders with at least 20 detections were included in analyses.

A road crossing was recorded if an individual was located on the opposite side of the road to its previous detection, or in the median if previously detected on a verge. Road crossings were classified as complete if they crossed the entire road, i.e. from verge to verge, or partial if they crossed one roadway of a dual-roadway road, i.e. from verge to median or median to verge. We modeled the probability that a squirrel glider crossed the road at least once in the survey period as a logistic regression. We modeled the probability that a squirrel glider crosses the road at least once as a function of the site type and sex of the glider. Hence, whether a squirrel glider, i, crossed or not is modeled as a draw from the Bernoulli distribution with parameter $\mathrm{p}$ :

$$
Z_{j} \sim \operatorname{Bernoulli}\left(p_{i}\right) .
$$

where $\operatorname{logit}(p i)=\operatorname{logit}(p c)+b_{t}\left(t_{i}\right)+b_{s}\left(s_{i}\right)$

where logit $(p c)$ is the intercept, $b_{t}\left(t_{j}\right)$ is the effect of site type $t_{i}$ and $b_{s}\left(s_{i}\right)$ is the effect of being sex $s_{i}$. The categorical variables $b_{t}\left(t_{i}\right)$ and $b_{s}\left(s_{i}\right)$ were modeled using a reference class, set arbitrarily to zero for the control site type and males. Hence $p c$ can be interpreted as the probability that a male crosses a control road. There was insufficient data to effectively fit a random effect for site.

We fitted the model using Open BUGS 3.0.3 (Spiegelhalter et al. 2007), a Bayesian data analysis package. To represent a lack of prior information, and to ensure that the parameter estimates were driven by the data, we used uniform prior distributions for the intercept term $p c$ and a normal distribution with mean zero and variance 1000 for the site type and sex coefficients. Parameter 
Fig. 3. Aerial photograph of each site type showing the intersection between a) the Hume Freeway and a secondary road with trees present in the center median of the freeway (Trees), b) the Hume Freeway and a secondary road with no trees present in the center median of the freeway (No-Trees), c) two secondary roads away from the Hume Freeway (control). (Source: GoogleTM 2009).
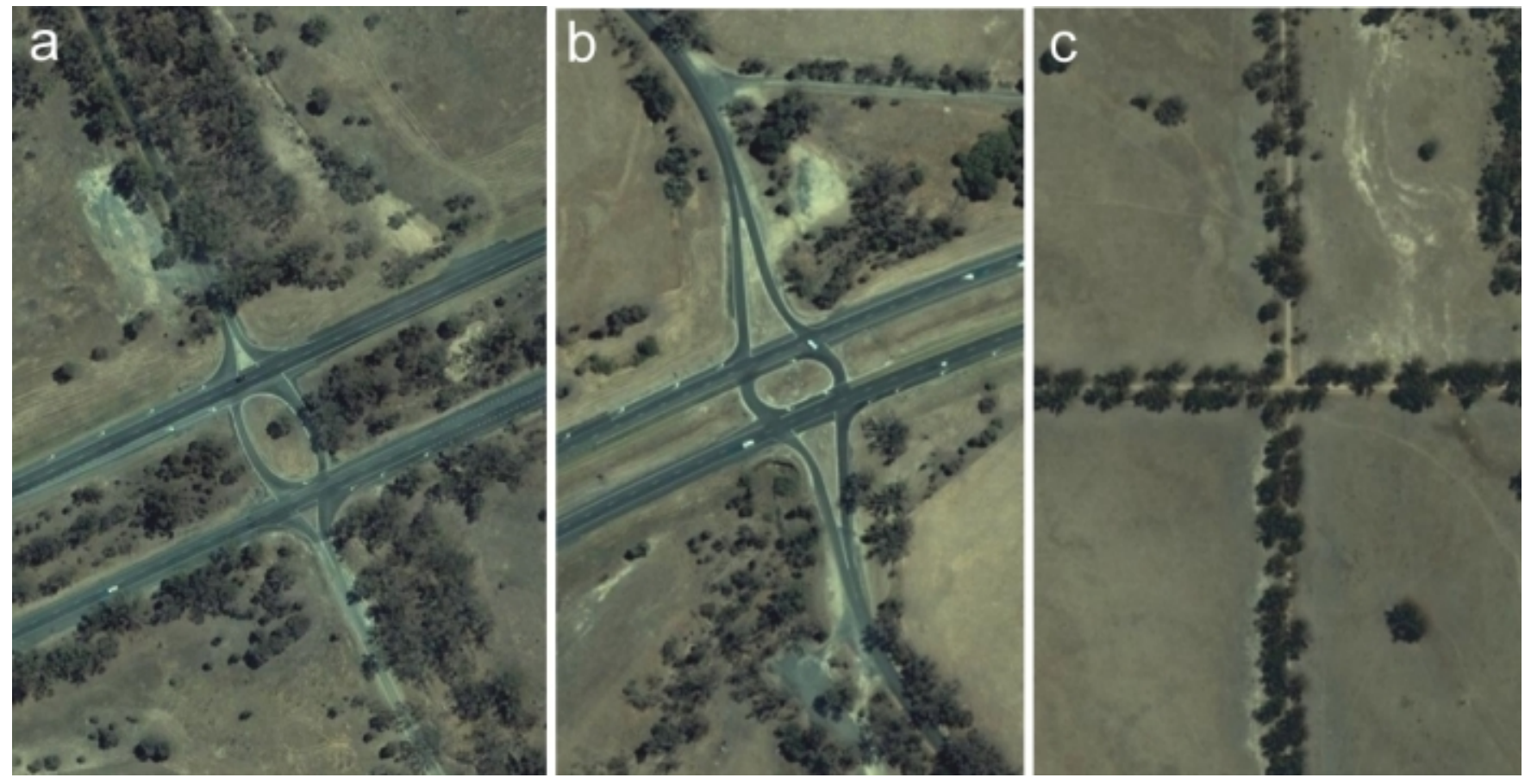

estimates are based on 20,000 samples from each of three chains after a 10,000 burn-in. The burn-in was more than sufficient for WinBUGS to reach stationarity. We used the DIC statistic to compare between models with different sets of explanatory variables (McCarthy 2007).

\section{RESULTS}

\section{Radio-tracking effort}

A total of 2155 fixes were obtained from 58 squirrel gliders (29 males and 29 females) that were fitted with radio-collars. Further analyses were undertaken on the 49 gliders for which we had at least 20 detections (25 females, 24 males). Two females, of the remaining 49, were detected $>250$ $\mathrm{m}$ from the road and were excluded from further analyses because their rate of crossing was likely limited because they did not have direct access to the freeway. The rate of road crossing between consecutive fixes was calculated for 47 gliders (24 males, 23 females; Table 1).
The number of radio-tracking fixes for each individual glider varied depending on the duration it carried the transmitter, and, if the collar was detached prematurely during the study, whether the individual was refitted with a transmitter. Of the 58 gliders fitted with radio transmitters, 24 carried transmitters until the end of the study, 21 were likely groomed off (with 13 remaining in tree hollows and 8 found on the ground), the signal of 12 transmitters was lost, i.e. could not be detected, and one transmitter was found with evidence consistent with predation by an owl. The proportion of individuals whose signal was lost and unaccounted for, i.e. cause of disappearance unknown, and were not retrapped at the conclusion of the study was similar across site types, with 0.26 and 0.33 at freeway sites with and without trees in the median, respectively, and 0.21 at control sites. However, variation in trapping effort among site types at the conclusion of the study complicates a reliable comparison of the rate of lost signals. 
Table 1. Summary of survey effort for 47 squirrel gliders (Petaurus norfolcensis) tracked along the Hume Freeway and at control sites, southeastern Australia from October 2005 to December 2006. n, number of individuals; fixes are number of detections from radio-tracking during the day (diurnal) or night (nocturnal) or from trapping; days, mean number of days on which fixes were obtained. Values are means $\pm 1 \mathrm{SE}$.

\begin{tabular}{lcrrrrr}
\hline \hline $\begin{array}{l}\text { Treatment and } \\
\text { sex }\end{array}$ & $\mathrm{n}$ & Diurnal fixes & Nocturnal fixes & Trapping fixes & Total fixes & Days \\
\hline Hume Freeway, tall trees in median $(\mathbf{n}=\mathbf{3})$ & & & & \\
Male & 7 & $9.4 \pm 3.0$ & $31.7 \pm 4.7$ & $2.7 \pm 0.7$ & 307 & $36.9 \pm 6.6$ \\
Female & 11 & $8.0 \pm 1.4$ & $31.5 \pm 3.4$ & $3.9 \pm 0.7$ & 469 & $35.8 \pm 3.9$
\end{tabular}

Hume Freeway, no tall trees in median $(\mathbf{n}=\mathbf{3})$

$\begin{array}{lcccccc}\text { Male } & 10 & 9.3 \pm 2.4 & 34.4 \pm 3.1 & 3.1 \pm 0.3 & 468 & 42.3 \pm 4.1 \\ \text { Female } & 6 & 10.2 \pm 2.8 & 36.7 \pm 3.6 & 2.8 \pm 0.6 & 298 & 44.5 \pm 4.5\end{array}$

Control sites $(n=2)$

$\begin{array}{lllllll}\text { Male } & 7 & 7.2 \pm 1.7 & 22.7 \pm 0.7 & 4.6 \pm 1.4 & 234 & 29.3 \pm 2.9 \\ \text { Female } & 6 & 8.2 \pm 1.8 & 22.8 \pm 0.8 & 5.2 \pm 1.3 & 217 & 32.3 \pm 1.4\end{array}$

\section{Probability of road crossing}

Fewer than half of the gliders (23 of 47) we tracked were detected making any type of road crossing. The proportion of gliders that crossed the road, completely or partially, varied among site types, with $77 \%$ of individuals at control sites crossing at least once, compared to $67 \%$ of individuals at freeway sites with trees in the median and 6\% at freeway sites without trees in the median (Table 2), with a higher proportion of males than females crossing (Fig. 4). At the freeway, the gliders who made complete crossings were a subset of those that made partial crossings (Table 2, Fig. 5), and all individuals that crossed the road returned to the side of the road where they had first been detected.

The logistic regression showed that there was no difference in the probability of crossing a secondary road or the two-way road with tall trees in the centre median (DIC full model: 44.25, DIC grouped model: 42.6; Fig. 6). However, there was a significant decrease in the probability of crossing highways without trees compared with the other two road types (Table 3). Males have a higher probability of crossing than females and both males and females are more likely to cross either the freeway with trees in the median or the secondary roads than the freeway without trees in the median. The parameter estimates for crossing a freeway with trees or secondary road are very broad (Fig. 6) reflecting considerable uncertainty regarding whether a given glider crosses or not. The low precision of the model may reflect that there are unmeasured processes that are not incorporated in this model or may be because of the small size of the dataset.

\section{DISCUSSION}

\section{Roads, traffic, gap size, and the barrier effect}

Roads and other linear infrastructure are ubiquitous components of most landscapes around the world and they have numerous and diverse effects on the 
Table 2. Classification of consecutive fixes of 47 squirrel gliders (Petaurus norfolcensis) tracked along the Hume Freeway and at secondary roads, southeastern Australia. n, number of individuals; fixes are detections from radio-tracking and trapping, with partial crossings from verge to median or median to verge at the dual-roadway freeway sites and full crossings from one shoulder to the opposite shoulder; total consecutive fixes is total fixes minus the first fix; and number of individuals detected crossing the road.

\begin{tabular}{|c|c|c|c|c|c|c|c|}
\hline \multirow{2}{*}{$\begin{array}{l}\text { Treatment } \\
\text { and sex }\end{array}$} & \multirow[t]{2}{*}{$\mathrm{N}$} & \multicolumn{3}{|c|}{ Classification of consecutive fixes } & \multirow{2}{*}{$\begin{array}{l}\text { Total } \\
\text { consecutive } \\
\text { fixes }\end{array}$} & \multicolumn{2}{|c|}{ Number of individuals undertaking } \\
\hline & & No crossing & $\begin{array}{l}\text { Partial } \\
\text { crossing }\end{array}$ & $\begin{array}{l}\text { Complete } \\
\text { crossing }\end{array}$ & & $\begin{array}{l}\text { Partial } \\
\text { crossing }\end{array}$ & $\begin{array}{l}\text { Complete } \\
\text { crossing }\end{array}$ \\
\hline \multicolumn{8}{|c|}{ Hume Freeway, tall trees in median $(n=3)$} \\
\hline Male & 7 & 226 & 60 & 14 & 300 & 6 & 4 \\
\hline Female & 11 & 358 & 90 & 10 & 458 & 6 & 3 \\
\hline \multicolumn{8}{|c|}{ Hume Freeway, no tall trees in median $(n=3)$} \\
\hline Male & 10 & 448 & 2 & 8 & 458 & 1 & 1 \\
\hline Female & 6 & 292 & 0 & 0 & 292 & 0 & 0 \\
\hline \multicolumn{8}{|c|}{ Secondary roads $(n=2)$} \\
\hline Male & 7 & 167 & na & 60 & 227 & NA & 7 \\
\hline Female & 6 & 192 & na & 19 & 211 & NA & 3 \\
\hline Totals & 47 & 1683 & 152 & 111 & 1946 & & \\
\hline
\end{tabular}

NA - partial crossings were not possible at secondary roads.

natural environment. Our results demonstrate that the movement patterns of squirrel gliders in southeastern Australia were disrupted by roads, with less than half (23 of 47) of the gliders for which we had sufficient data making any crossings. The effect of the road was more evident on complete crossings, with just 18 gliders detected on opposite sides of the road. Roads and other linear infrastructure have created artificial boundaries to home ranges and influenced patterns of activity and habitat utilization in a range of species (Fahrig and Rytwinski 2009, Benítez-López et al. 2010).
The barrier or filter effect of roads on the movement of wildlife has been demonstrated for a wide range of species, including small mammals (Oxley et al. 1974, Mader 1984, Burnett 1992), carnivores (Alexander et al. 2005, Riley et al. 2006), ungulates (Alexander et al. 2005), birds (Develey and Stouffer 2001), and arboreal mammals (Gulle 2006, Wilson et al. 2007). The movement and dispersal of animals among local populations is important to reduce the risk of local extinction (Fahrig 2003) and maintain the viability of the metapopulation (Hanski 1999). The maintenance of existing links and establishment of new links across an urbanizing landscape were 
Fig. 4. Proportion of squirrel gliders (Petaurus norfolcensis) that were observed crossing (complete and partial crossings) the Hume Freeway or at secondary roads (control). Males are shown in black, females in clear. Number of gliders in each treatment is shown above columns.

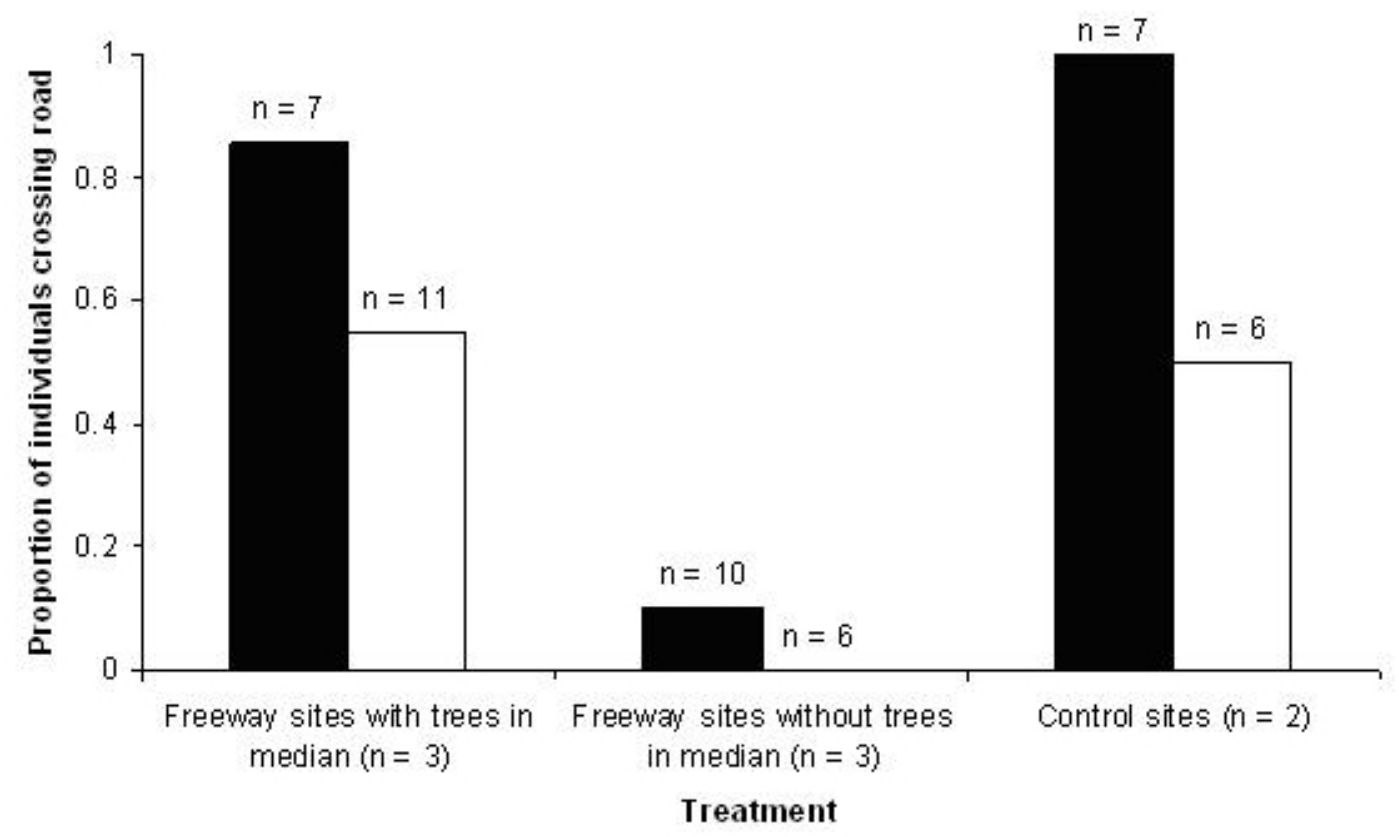

some of the best predictors influencing the persistence of squirrel gliders in Thurgoona, approximately $150 \mathrm{~km} \mathrm{NE}$ of our study area (Stewart and van der Ree 2009). A population viability analysis (PVA) for the Greater Glider (Petauroides volans) in Brisbane, NE Australia, similarly predicted that even a low rate of dispersal across a motorway using crossing structures was sufficient to reduce the risk of local extinction to an acceptable level (Taylor and Goldingay 2009).

The predicted probability of an individual crossing the road was the same for animals at the secondary road and animals at the freeway with trees in the median. However, the likelihood that an individual would cross at the freeway without trees in the median was significantly lower than the other two site types. This result strongly suggests that the size of the gap in canopy was the primary determinant of the rate of crossing by gliders. Also, the only difference between freeway sites with and without trees in the median was the size of the gap to be traversed, which was more than quadrupled when trees were absent from the median. There is a physical limit to the length of glides, which is dependent on species morphology, (e.g., body weight, shape and size), launch height, and presumably wind conditions. Although squirrel gliders are physically capable of glides of up to 70 $\mathrm{m}$ across cleared farmland (van der Ree et al. 2003), typical glide lengths are 20 - 35 m (Jackson 1999, van der Ree et al. 2003, Goldingay and Taylor 2009), less than half that required to cross the freeway in the absence of a median with trees. Although reliable data on the gliding capability of squirrel gliders in fragmented habitat is lacking (but see Jackson 1999 for data on glide capability in other species or in continuous habitat, Goldingay and Taylor 2009), even the most conservative estimates suggest that canopy gaps across freeways with trees in the median strip are sufficiently small for average gliders to cross (Goldingay and Taylor 2009). Further work is clearly required to quantify the glide capability in fragmented habitat, as average glide distance may be underestimated because trees in continuous forest are spaced closer together. Gliders may be forced to undertake longer glides in fragmented habitat because trees are spaced further apart. However, it is important to design mitigation strategies for average individuals within the 
Fig. 5. Proportion of fixes for 23 squirrel gliders (Petaurus norfolcensis) that made partial (clear columns) and complete (solid columns) crossings of the Hume Freeway at sites with and without tall trees in the centre median (Trees and No Trees, respectively) and secondary roads (Control). Sex of individuals is given on $\mathrm{X}$-axis and total number of detections given above each column. Data for animals that were not detected crossing is not shown.

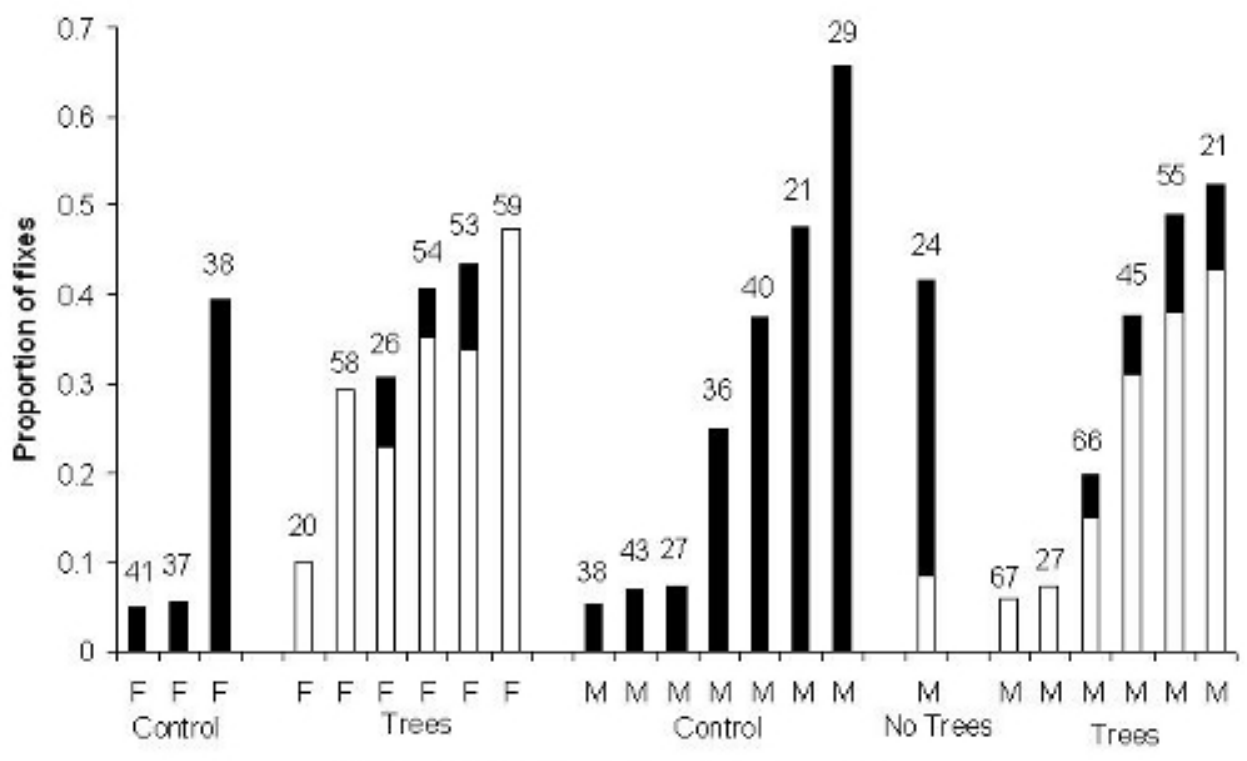

Squirrel Glider individuals that crossed the road

population and typical glides, rather than individuals with extreme performances or undertaking exceptional activities.

It was surprising that traffic volume and road substrate appeared to have only a minor influence on crossing by squirrel gliders because the effects of traffic, i.e., volume, light, noise, and/or the physical presence of the road affect the rate of crossing in other species. For example, inhibition of road crossing has been attributed to avoidance of the road substrate (Merriam et al. 1989, Brock and Kelt 2004, Shine et al. 2004), traffic noise (e.g., Foppen and Reijnen 1994), or exposure to habitat edge (Goosem 2001, Laurance et al. 2004). Two squirrel gliders were observed crossing the freeway by gliding from a tree in the center median to a tree on the verge and we assume that most crossings occurred in a similar way, i.e., without coming to ground. Thus, the road substrate (bitumen or gravel) is unlikely to influence the rate of crossing. Traffic volume (up to 5,000 vpd per roadway) and traffic per se, i.e., the sight, noise, and headlights of vehicles, did not appear to greatly influence the rate of crossing by gliders. Squirrel gliders are nocturnal and hence the relevant consideration is the traffic volume during the night. Approximately onequarter of the daily traffic along the Hume Freeway occurs between $10 \mathrm{pm}$ and 5 am (1250 vehicles per roadway over a seven-hour period), which equates to one vehicle per 3 minutes, with longer intervals between vehicles likely. For a gliding species, three minutes is sufficient to safely glide across a roadway between vehicles. Identifying the relationship between traffic volume and road crossing is an important area of research because it focuses the type of mitigation that may be successful (McGregor et al. 2008).

The only individual to cross the Hume Freeway in the absence of tall trees in the median was male, and he is likely to represent an extreme performance that appears atypical to the rest of the population. This male also had the highest rate (33\% of 24 fixes) of complete crossings at the Hume Freeway. Although unusual, this extreme case of gliding ability and/or willingness is not unique, as a male squirrel glider that regularly crossed the nearby Goulburn Valley 
Fig. 6. Mean predicted probability that a squirrel glider (Petaurus norfolcensis) resident in habitat adjacent to a road will make a partial, i.e., verge to median or median to verge, or complete crossing at different site types. There was no significant difference in the likelihood that an individual will cross a secondary road or the dual-roadway Hume Freeway with trees in the median, and these are pooled (denoted Control/Trees). No Trees are sites at the Hume Freeway without trees in the median. Males and females are shown. Error bars are the $95 \%$ credible intervals.

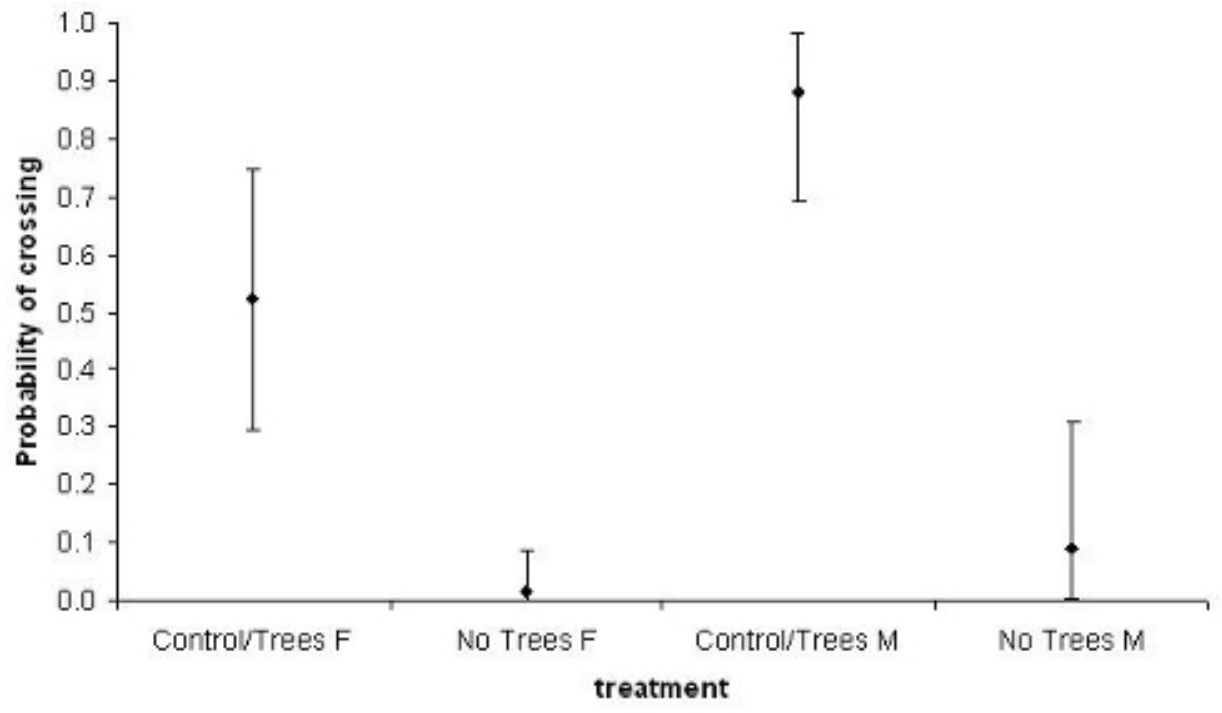

Freeway, a two-way road, raised onto two bridges, was similarly extreme in its performance (van der Ree 2006). The wide range in the rate of crossing by individuals, i.e., 24 showing no crossing, and the rate of crossing ranging from 0.05 to 0.65 for the remainder, clearly demonstrates individual variability in the propensity to cross the road. Some of the variation in the rate of crossing may also be explained by the spatial arrangement of home ranges and the extent to which they abut or overlap the road.

The rate of loss of the signal from transmitters was highest at the freeway without trees in the median $(0.33)$, intermediate at the freeway with trees in the median (0.26), and lowest at the intersection of two secondary roads (0.21). Although sample sizes are small, this trend is consistent with estimates of the apparent survival rate of adult squirrel gliders at the Hume Freeway being one-third that of populations living along secondary roads far from the freeway (McCall et al. 2010). Apparent survival rate is due to true survival and site fidelity, indicating a higher probability that a squirrel glider will leave a population near a major road, via mortality or dispersal, than one located further from a major road. The rate of road mortality of squirrel gliders is difficult to quantify because individuals that collide with vehicles are either thrown into the adjacent vegetation or damaged beyond recognition. Active searches for dead gliders were carried out when signals from transmitters were lost, and no remains were found to suggest collision with vehicles.

\section{Management implications}

Our study demonstrates that the width of linear infrastructure is an important factor influencing the daily movements of squirrel gliders. Although other studies have shown that there may be threshold effects associated with the volume of traffic (Reijnen et al. 1995, Gagnon et al. 2007), we were unable to detect any effect of traffic volume in our study. However, a threshold effect of traffic volume on crossing rates is likely because increases in traffic volume will reduce the length of the interval between cars. The continual growth in the length and width of roads and other linear infrastructure, such as train lines and utility easements, is concerning for the conservation of biodiversity because of the potential impacts on fauna, flora, and ecosystem processes. 
Table 3. The results of the logistic model of the probability that a squirrel glider (Petaurus norfolcensis) crosses the road. Parameter estimates for the three terms in the logistic model (logit(pc), bt and bs - see methods) are shown, as well as the resulting predictions for the probability of crossing for the four different cases.

\begin{tabular}{lcccccc}
\hline \hline Parameter & Mean & SD & CI (2.5\%) & Median & CI (97.5\%) & Sample \\
\hline logit(pc) & 2.22 & 0.84 & 0.8123 & 2.1440 & 4.1070 & 60000 \\
$\mathrm{~b}_{\mathrm{t}}$ & -5.04 & 1.50 & -8.4070 & -4.8740 & -2.5880 & 60000 \\
$\mathrm{~b}_{\mathrm{s}}$ & -2.12 & 0.96 & -4.1810 & -2.0510 & -0.4047 & 60000 \\
$\mathrm{pc}$ [control/trees, male] & 0.88 & 0.08 & 0.6926 & 0.8952 & 0.9838 & 60000 \\
$\mathrm{pc}[$ control/trees, female] & 0.52 & 0.12 & 0.2943 & 0.5245 & 0.7463 & 60000 \\
$\mathrm{pc}[$ no trees, female] & 0.02 & 0.02 & 0.0002 & 0.0083 & 0.0870 & 60000 \\
$\mathrm{pc}[$ no trees, male] & 0.09 & 0.08 & 0.0027 & 0.0671 & 0.3080 & 60000 \\
\hline
\end{tabular}

The wide range in the rate of crossing by individuals, from 24 animals with no crossings to $65 \%$ of fixes resulting in a crossing, has important implications for management. The maintenance of sufficient dispersal and gene flow across the Hume Freeway is likely to be facilitated by the presence of tall trees in the median because males and females both made complete and partial crossings. Although we did not follow the movement of dispersing individuals, they are more likely to travel further and take greater risks while dispersing than the adults we tracked (R. van der Ree, unpublished data). However, this question is best explored using genetic techniques (Simmons et al. 2010), which are currently underway at our sites. No gliders were detected making daily crossings of the Hume Freeway. It is unclear if this lack of regular movement is because important resources were distributed on both sides of the freeway or because a median strip with tall trees, or timber poles to act as artificial trees (Ball and Goldingay 2008), is not an effective form of mitigation to allow daily movements. Other techniques, such as aerial rope bridges (e.g., Soanes and van der Ree 2009) or vegetated land bridges may be necessary if the goal of mitigation is to allow all individuals within a population to cross the road for daily foraging requirements.

The type of mitigation used to restore connectivity for gliders must take into account any potential increase in mortality because of collision with vehicles. Although tall trees, and potentially glider poles, on the verge of the road and in the centre median may facilitate a similar rate of crossing to that at secondary roads with low volumes of traffic, it may also increase the rate of mortality by allowing animals to attempt the glide across the road, increasing the probability of collision with a vehicle. Further research is required to determine the relative importance of each threat to a population, and thus determine specific goals for mitigation, which is likely to include a combination of reducing mortality and restoring connectivity. From a conservation perspective, the overarching goal for all mitigation works must be to increase the viability of a population (van der Ree et al. 2007) and this could be achieved by increasing connectivity or reducing mortality. For example, a model to guide the reintroduction of the Eurasian lynx (Lynx lynx) in Germany required connectivity between habitat and a reduction in road mortality to maintain a viable metapopulation (Kramer-Schadt et al. 2004). There is now sufficient compelling evidence that roads and traffic have negative population-level effects on wildlife (Fahrig and Rytwinski 2009) and that quantification and mitigation of the specific threat should be routine in all road construction and maintenance projects. 
Responses to this article can be read online at: http://www.ecologyandsociety.org/voll5/iss4/art35/ responses/

\section{Acknowledgments:}

We thank The Baker Foundation, The Australian Research Centre for Urban Ecology, the Australian Research Council (grant LP0560443 to MB, RvdR, AT and PS), and VicRoads for financial support. All animals were trapped under the University of Melbourne Animal Ethics Committee permit number 05141 and the Department of Sustainability and Environment wildlife research permit number 10003061. Peter Crowcroft, Inneke Nathan, Sarah McCall, and J. Squire provided valuable help in the collection of data.

\section{LITERATURE CITED}

Alexander, S. M., N. M. Waters, and P. C. Paquet. 2005. Traffic volume and highway permeability for a mammalian community in the Canadian Rocky Mountains. The Canadian Geographer 49:321-331.

Ball, T., and R. Goldingay. 2008. Can wooden poles be used to reconnect habitat for a gliding mammal? Landscape and Urban Planning 87:140-146.

Benítez-López, A., R. Alkemade, and P. A. Verweij. 2010. The impacts of roads and other infrastructure on mammal and bird populations: a meta-analysis. Biological Conservation 143:1307-1316.

Brock, R. E., and D. A. Kelt. 2004. Influence of roads on the endangered Stephens' kangaroo rat (Dipodomys stephensi): are dirt and gravel roads different? Biological Conservation 118:633-640.

Burnett, S. E. 1992. Effects of a rainforest road on movements of small mammals: mechanisms and implications. Wildlife Research 19:95-104.

Claridge, A. W., and R. van der Ree. 2004. Recovering endangered populations in fragmented landscapes: the squirrel glider Petaurus norfolcensis on the south-west slopes of New South Wales. Pages 678-687 in D. Lunney, editor. Conservation of Australia's forest fauna. Second Edition. Royal
Zoological Society of New South Wales, Mosman, New South Wales, Australia.

Coffin, A. W. 2007. From roadkill to road ecology: a review of the ecological effects of roads. Journal of Transport Geography 15:396-406.

Develey, P. F., and P. C. Stouffer. 2001. Effects of roads on movements by understory birds in mixedspecies flocks in central Amazonian Brazil. Conservation Biology 15:1416-1422.

Eigenbrod, F., S. J. Hecnar, and L. Fahrig. 2008. The relative effects of road traffic and forest cover on anuran populations. Biological Conservation 141:35-46.

Epps, C. W., P. J. Palsboll, J. D. Wehausen, G. K. Roderick, R. R. Ramey, and D. R. McCullough. 2005. Highways block gene flow and cause a rapid decline in genetic diversity of desert bighorn sheep. Ecology Letters 8:1029-1038.

Fahrig, L. 2003. Effects of habitat fragmentation on biodiversity. Annual Review of Ecology Evolution and Systematics 34:487-515.

Fahrig, L., and T. Rytwinski. 2009. Effects of roads on animal abundance: an empirical review and synthesis. Ecology And Society 14(1):21 (online) URL: http://www.ecologyandsociety.org/vol14/iss1/ art21/.

Foppen, R., and R. Reijnen. 1994. The effects of car traffic on breeding bird populations in woodland .II. Breeding dispersal of male willow warblers (Phylloscopus trochilus) in relation to the proximity of a highway. Journal of Applied Ecology 31:95-101.

Ford, A. T., and L. Fahrig. 2008. Movement patterns of Eastern Chipmunks (Tamias striatus) near roads. Journal of Mammalogy 89:895-903.

Gagnon, J. W., T. C. Theimer, N. L. Dodd, S. Boe, and R. E. Schweinsburg. 2007. Traffic volume alters elk distribution and highway crossings in Arizona. Journal of Wildlife Management 71:2318-2323.

Goldingay, R. L., and B. D. Taylor. 2009. Gliding performance and its relevance to gap crossing by the squirrel glider (Petaurus norfolcensis). Australian Journal Of Zoology 57:99-104. 
Goosem, M. 2001. Effects of rainforest roads on small mammals: inhibition of crossing movements. Wildlife Research 28:351-364.

Gulle, N. 2006. Home range use and road crossing behaviour by the common brushtail possum Trichosurus vulpecula. Thesis. School of Botany, University of Melbourne, Parkville, Australia.

Hanski, I. 1999. Metapopulation Ecology. Oxford University Press, Oxford, UK.

Hels, T., and G. Nachman. 2002. Simulating viability of a spadefoot toad Pelobates fuscus metapopulation in a landscape fragmented by a road. Ecography 25:730-744.

Holland, G., A. F. Bennett, and R. van der Ree. 2007. Time-budget and foraging behaviour of the squirrel glider, Petaurus norfolcensis, in remnant linear habitat. Wildlife Research 34:288-295

Jackson, S. M. 1999. Glide angle in the genus Petaurus and a review of gliding in mammals. Mammal Review 30:9-30.

Jaeger, J. A. G., J. Bowman, J. Brennan, L. Fahrig, D. Bert, J. Bouchard, N. Charbonneau, K. Frank, B. Gruber, and K. T. von Toschanowitz. 2005. Predicting when animal populations are at risk from roads: an interactive model of road avoidance behavior. Ecological Modelling 185:329-348.

Jaeger, J. A. G., and L. Fahrig. 2004. Effects of road fencing on population persistence. Conservation Biology 18:1651-1657.

Kramer-Schadt, S., E. Revilla, T. Wiegand, and U. Breitenmoser. 2004. Fragmented landscapes, road mortality and patch connectivity: modelling influences on the dispersal of Eurasian lynx. Journal of Applied Ecology 41:711-723.

Laurance, S. G. W., P. C. Stouffer, and W. E. Laurance. 2004. Effects of road clearings on movement patterns of understorey rainforest birds in central Amazonia. Conservation Biology 18:1099-1109.

Lengagne, T. 2008. Traffic noise affects communication behaviour in a breeding anuran, Hyla arborea. Biological Conservation 141:2023-2031.
Litvaitis, J. A., and J. P. Tash. 2008. An approach toward understanding wildlife-vehicle collisions. Environmental Management 42:688-697.

Mader, H. J. 1984. Animal habitat isolation by roads and agricultural fields. Biological Conservation 29:81-96.

Marsh, D. M., R. B. Page, T. J. Hanlon, R. Corritone, E. C. Little, D. E. Seifert, and P. R. Cabe. 2008. Effects of roads on patterns of genetic differentiation in red-backed salamanders, Plethodon cinereus. Conservation Genetics 9:603-613.

McCall, S. C., M. A. McCarthy, R. van der Ree, M. J. Harper, S. Cesarini, K. Soanes. 2010. Evidence that a highway reduces apparent survival rates of squirrel gliders. Ecology and Society $\mathbf{1 5}$ (3):27. [online] URL: http://www.ecologyandsociety. org/vol15/iss $3 / \operatorname{art} 27 /$.

McCarthy, M. A. 2007. Bayesian methods for ecology. Cambridge University Press, Cambridge, UK.

McGregor, R. L., D. J. Bender, and L. Fahrig. 2008. Do small mammals avoid roads because of the traffic? Journal of Applied Ecology 45:117-123.

Merriam, G., M. Kozakiewicz, E. Tsuchiya, and K. Hawley. 1989. Barriers as boundaries for metapopulations and demes of Peromyscus leucopus in farm landscapes. Landscape Ecology 2:227-235.

Oxley, D. J., M. B. Fenton, and G. R. Carmody. 1974. The effects of roads on populations of small mammals. Journal of Applied Ecology 11:51-59.

Reijnen, R., R. Foppen, C. Terbraak, and J. Thissen. 1995. The effects of car traffic on breeding bird populations in woodland. III. Reduction of density in relation to the proximity of main roads. Journal of Applied Ecology 32:187-202.

Riley, S. P. D., J. P. Pollinger, R. M. Sauvajot, E. C. York, C. Bromley, T. K. Fuller, and R. K. Wayne. 2006. A southern California freeway is a physical and social barrier to gene flow in carnivores. Molecular Ecology 15:1733-1741.

Roedenbeck, I. A., L. Fahrig, C. S. Findlay, J. E. Houlahan, J. A. G. Jaeger, N. Klar, S. Kramer- 
Schadt, and E. A. van der Grift. 2007. The Rauischholzhausen agenda for road ecology. Ecology and Society 12(1):11. [online] URL: http:/ /www.ecologyandsociety.org/vol12/iss1/art11/.

Rondinini, C., and C. P. Doncaster. 2002. Roads as barriers to movement for hedgehogs. Functional Ecology 16:504-509.

Shine, R., M. Lemaster, M. Wall, T. Langkilde, and R. Mason. 2004. Why did the snake cross the road? Effects of roads on movement and location of mates by garter snakes (Thamnophis sirtalis parietalis). Ecology and Society 9(1):9. [online] URL: http://www.ecologyandsociety.org/vol9/iss1/ art9/.

Simmons, J., P. Sunnucks, A. C. Taylor, and R. van der Ree. 2010. Beyond roadkill, radiotracking, recapture and $\mathrm{F}_{\mathrm{ST}}-\mathrm{a}$ review of some recent genetic methods to improve understanding of the influence of roads on wildlife. Ecology And Society 15(1):9 (online) URL: http://www.ecologyandsociety.org/vol15/ iss1/art9/.

Soanes, K., and R. van der Ree. 2009. Highway impacts on arboreal mammals and the use and effectiveness of novel mitigation techniques. Pages 441-451 in P. J. Wagner, D. Nelson, and E. Murray, editors. International Conference on Ecology and Transportation. Duluth, Minnesota, USA.

Spiegelhalter, D., A. Thomas, N. Best, and D. Lunn. 2007. Open BUGS User Manual, Version 3.0.2. MRC Biostatistics Unit, Cambridge, UK.

Steen, D. A., M. J. Aresco, S. G. Beilke, B. W. Compton, E. P. Condon, C. K. Dodd, H. Forrester, J. W. Gibbons, J. L. Greene, G. Johnson, T. A. Langen, M. J. Oldham, D. N. Oxier, R. A. Saumure, F. W. Schueler, J. M. Sleeman, L. L. Smith, J. K. Tucker, and J. P. Gibbs. 2006. Relative vulnerability of female turtles to road mortality. Animal Conservation 9:269-273.

Stewart, C. W., and R. van der Ree. 2009. Population viability analysis for squirrel gliders in the Thurgoona and Albury Ranges region of New South Wales. Australian Research Centre for Urban Ecology, Melbourne, Australia.

Tanner, D., and J. Perry. 2007. Road effects on abundance and fitness of Galapagos lava lizards
(Microlophus albermarlensis). Journal of Environmental Management 85:270-278.

Taylor, B. D., and R. Goldingay. 2009. Can road crossing structures improve viability of an urban gliding mammal? Ecology And Society 14(2):13. [online] URL: http://www.ecologyandsociety.org/voll4/ iss $2 / \operatorname{art} 13 /$.

van der Ree, R. 2006. Road upgrade in Victoria a filter to the movement of the endangered squirrel glider Petaurus norfolcensis: results of a pilot study. Ecological Management and Restoration 7:226-228.

van der Ree, R., and A. F. Bennett. 2001. Woodland remnants along roadsides: a reflection of pre-European structure in temperate woodlands? Ecological Management \& Restoration 2:224-226.

van der Ree, R., and A. F. Bennett. 2003. Home range of the squirrel glider Petaurus norfolcensis in a network of linear habitats. Journal of Zoology (London) 259:327-336.

van der Ree, R., A. F. Bennett, and D. C. Gilmore. 2003. Gap-crossing by gliding marsupials: thresholds for use of isolated woodland patches in an agricultural landscape. Biological Conservation 115:241-249.

van der Ree, R., M. Harper, and M. Crane. 2006. Longevity in wild populations of the squirrel glider Petaurus norfolcensis. Australian Mammalogy 28:239-242.

van der Ree, R., and G. C. Suckling. 2008. Squirrel glider. Pages 235-236 in S. V. Dyck and R. Strahan, editors. The mammals of Australia. New Holland Publishers, Sydney, Australia.

van der Ree, R., E. A. van der Grift, C. Mata, and F. Suarez. 2007. Overcoming the barrier effect of roads - how effective are mitigation strategies? An international review of the effectiveness of underpasses and overpasses designed to increase the permeability of roads for wildlife. Pages 423-431 in C. L. Irwin, D. Nelson, and K. P. McDermott, editors. International Conference on Ecology and Transportation. Center for Transportation and The Environment, North Carolina State University, Raleigh, NC, Little Rock, Arkansas, USA.

van der Ree, R., S. J. Ward, and K. Handasyde. 2004. Distribution and conservation status of 
possums and gliders in Victoria. Pages 91-110 in R. L. Goldingay and S. Jackson, editors. The biology of Australian possums and gliders. Surrey Beatty and Sons PTY, Chipping Norton, Australia.

Wilson, R. F., H. Marsh, and J. Winter. 2007. Importance of canopy connectivity for home range and movements of the rainforest arboreal ringtail possum (Hemibelideus lemuroides). Wildlife Research 34:177-184. 